\title{
Neural Networks in Corporate Governance Systems
}

\author{
Rizvan Turluev ${ }^{1}$, and Laura Hadjieva ${ }^{2}$ \\ ${ }^{1}$ Chechen State University, 364024 Grozny, Russia \\ ${ }^{2}$ Grozny State Oil Technical University, 364061 Grozny, Russia
}

\begin{abstract}
Every year, the interest in solving more complex problems is growing, due to automation, the need for communication processes in intelligent systems. One of the promising directions for solving this problem is based on the use of artificial neural networks and neurocomputers, as the most progressive in relation to corporate governance problems.
\end{abstract}

\section{Introduction}

In the modern world, it is very important that management decisions are effective, since they allow the company to get the maximum possible profit. The algorithm for making a managerial decision consists of the subject receiving information, processing it and ultimately making a decision. However, there can be a lot of information. This means that the one who must make a decision will not be able to cover all the information and draw the correct conclusions, so he will shorten and simplify this information, which will lead to its distortion and the construction of an inaccurate mathematical model. The solution to this and many other problems lies in the use of artificial neural networks, which determines, in particular, the relevance of studying their use in the mechanism of making managerial decisions at an enterprise.

The study of artificial neural networks began recently with the works of W. McCulloch and W. Pitts (1943), who formed the concept of "neural network". Such prominent scientists as N. Wiener, D. Hebb, F. Rosenblatt, T. Kohonen, J. Anderson and others were also engaged in the study of artificial neural systems. Since enterprise management is a very important activity, the main task is to improve the efficiency of this management. The questions of applying the methods by which this efficiency can be achieved remain unresolved.

\section{Materials and methods}

Quantitative and qualitative parameterization on the evidence-based analytical basis for choosing a strategy, developing indicative plans and business planning, forming a long-term business partnership strategy, evaluating the implementation of a strategy occurs within two processes. 
The first is the formulation process - this is a cognitive and decisive process aimed at defining the main strategic goals of the enterprise and identifying the main obstacles to achieving them.

The second is the implementation process - this is the development of measures, the application of which will lead to the achievement of the planned strategic goals:

- economic (high level of profitability and profitability, economic potential and effective sources of financing, availability of solvency);

- technical and technological (the presence of advanced software for the management system, a low level of wear and tear of fixed assets, but not material assets, a high level of information support through the use of information technology);

- organizational and managerial (high level of corporate culture, effective organizational structure, degree of staff motivation, professional competence of management);

- marketing (availability of an effective strategy for promoting products to the market, optimal pricing policy, developed trade and representative network, well-known brand, positive business image);

- socio-psychological (psychological mood of consumers of goods, trust from the population, etc.);

- geographical (the geographical presence of a trading enterprise in regions with a developed market infrastructure and effective consumer demand).

The issue of analytical substantiation of competitive strategy is reflected in many scientific developments of such domestic and foreign scientists as: P.L. Gordienko, I. Ansoff, L. Karmin, N. I. Kostina, L. Kostyrko, N.V. Kudenko, K. I. Redchenko, V. D. Nemtsov, E.M. Sych, S. I. Shkaraban and others. However, in the above-mentioned works, analytical support is distinguished only in the plane of choice and justification of the strategy of activity, or in the operational analysis of planned and regulated activities. Diagnostics of possible maneuvering in achieving strategic goals, assessing the integration of strategy and tactics of entrepreneurship, risk analysis of tactical decisions based on criteria for achieving a strategic goal, and the like, remain without attention. The solution of these problems will allow achieving transparency, convincing strategic and tactical management and minimizing the risk of achieving the goal of the activity. Therefore, it is proposed to use a mathematical apparatus - the theory of fuzzy sets, used in their research by such researchers as V.V. Kruglov, V.I. Bozhich, O.B. Lebedev, Yu.L. Shnitser, A.A. Zorina. [2, 4, 5, 6] and others.

\section{Results and discussion}

Artificial neural networks are mathematical models, as well as their software or hardware implementations, built on the principle of the organization and functioning of biological neural networks - networks of nerve cells of a living organism [7].

They arose in connection with the study of processes occurring in the human brain, as well as with the ability to predict them. The principle of operation of such a neuron is as follows:

input signals (xn) having corresponding weights (wn) are composed and passed through the transfer function, generate a result, and finally an output result is obtained.

In addition, all neurons are interconnected and make up certain layers that form an artificial neural network. The input layer receives information from the external environment and transfers it to the next level, where it is analyzed and processed. After that, from the intermediate layer, the already processed information enters the output layer, from which directly to the external environment. The transfer of information from one neuron to another is an important aspect of the activity of neural networks. 
In general, the stages of solving problems using artificial neural networks are [7]:

1. Collecting data for training.

2. Preparation and normalization of data.

3. Choice of network topology.

4. Experimental selection of network characteristics.

5. Experimental selection of training parameters.

6. The learning process.

7. Checking the adequacy of training.

8. Correction of parliaments, final learning.

9. Verbalization of the network for further use.

Artificial neural networks solve a wide range of tasks in accordance with the functions they perform.

So, artificial neural networks perform a lot of functions that can be applied by management to solve specific problems facing the enterprise.

In general, in our opinion, the use of neural networks provides certain advantages for enterprises that use, in particular:

- the possibility of using for problems with incomplete information, when traditional mathematical models do not give the desired result;

- improving the accuracy of the solution and reducing its subjectivity;

- a more detailed study of processes and situations;

- use various methods of analysis and a large number of algorithms;

- the ability to solve those tasks that were not previously solved;

- acceleration of the decision-making process, etc.

So, artificial neural networks allow you to achieve a new quality of work, get an economic effect from their implementation or organize the decision-making process in a new way.

Table 1. Main functions of artificial neural networks

\begin{tabular}{|c|c|c|}
\hline Function & Content & Application \\
\hline Image classification & $\begin{array}{c}\text { determining the membership of the } \\
\text { input image represented by the feature } \\
\text { vector to one or more predefined } \\
\text { classes; }\end{array}$ & $\begin{array}{l}\text { recognition of letters, } \\
\text { language. }\end{array}$ \\
\hline $\begin{array}{l}\text { Clustering / } \\
\text { categorization }\end{array}$ & $\begin{array}{l}\text { assignment of similar images to one } \\
\text { cluster; }\end{array}$ & $\begin{array}{c}\text { to gain knowledge, compress } \\
\text { data and study their } \\
\text { properties. }\end{array}$ \\
\hline $\begin{array}{c}\text { Function } \\
\text { approximation }\end{array}$ & $\begin{array}{l}\text { finding an unknown function } \mathrm{F} \\
\text { distorted by noise; }\end{array}$ & for modeling tasks. \\
\hline Forecast / predictions & $\begin{array}{l}\text { predicting values in a subsequent } \\
\text { period of time; }\end{array}$ & $\begin{array}{l}\text { for decision making in } \\
\text { business, science and } \\
\text { technology. }\end{array}$ \\
\hline Optimization & $\begin{array}{l}\text { finding a solution that satisfies the } \\
\text { system of constraints and maximizes } \\
\text { or minimizes the objective function; }\end{array}$ & $\begin{array}{l}\text { to optimize problems in } \\
\text { mathematics, statistics, } \\
\text { economics, etc. }\end{array}$ \\
\hline Associative memory & $\begin{array}{l}\text { finding the required document for a } \\
\text { given content; }\end{array}$ & $\begin{array}{l}\text { multimedia information } \\
\text { databases. }\end{array}$ \\
\hline Control & $\begin{array}{l}\text { calculation of such an input action, at } \\
\text { which the system acts along the } \\
\text { desired trajectory, given by the } \\
\text { reference model; }\end{array}$ & management of devices. \\
\hline
\end{tabular}


Table 2. Use of artificial neural networks

\begin{tabular}{|c|c|}
\hline Task & Example \\
\hline Price and production management & $\begin{array}{c}\text { A system for planning prices and costs } \\
\text { (the relationship between advertising } \\
\text { costs, sales volume, competitors' prices, } \\
\text { product prices, etc.), on the basis of which } \\
\text { the optimal strategy is selected in terms of } \\
\text { maximizing profits or sales. }\end{array}$ \\
\hline Determination of factors influencing \\
demand & $\begin{array}{c}\text { Forecasting consumer behavior when } \\
\text { changing marketing policy, finding the } \\
\text { optimal advertising strategy, determining } \\
\text { the segment of the most promising } \\
\text { consumers for a given product. }\end{array}$ \\
\hline Property valuation & $\begin{array}{c}\text { Determination of the market value of } \\
\text { offices, industrial premises or land on the } \\
\text { basis of a comparative approach. }\end{array}$ \\
\hline Consumer market analysis & $\begin{array}{c}\text { Assessment of consumers in terms of the } \\
\text { likelihood of purchasing a particular } \\
\text { product. }\end{array}$ \\
\hline Anti-fraud & $\begin{array}{c}\text { processing transactions with the } \\
\text { assignment of each transaction to the } \\
\text { appropriate risk level. The spectrum of } \\
\text { fraud prevention systems extends from } \\
\text { healthcare fraud to the credit sector. }\end{array}$ \\
\hline
\end{tabular}

Data storage is the cornerstone of business intelligence systems. $87 \%$ of companies have one or more functioning data warehouses, with more than half having more than one such warehouse. In fact, every four companies have twenty or more storages that are logically integrated in some way, $18 \%$ of these storages are terabytes or more, $30 \%$ of respondents expect their data storage to double or even multiply in the next two or three of the year. The variety of data sources that fill the store is simply amazing. Naturally, each warehouse uses transactional systems as a data source. However, several unusual data sources are known, such as e-commerce websites (51\%), bindings to databases hosted by customers or business partners (49\%), and accessibility services that provide characteristic customer information (47\%), Web site content retrieval (41\%), search / discovery services (34\%), and news feeds from major news agencies (33\%). Finally, $47 \%$ of companies have one or more data marts, and $49 \%$ use operational data stores.

Concept author Bill Inmona, in his classic article What Are Data Warehouses [10], defines data warehouses as "domain-specific, integrated, immutable, historical datasets organized to support governance." He views the repositories as "the one and only source of truth", the "center of the universe" of decision support systems (DSS). "From data warehouses," he writes, "information flows to various departments, being filtered in accordance with the specified DSS settings. These separate databases for decision-making are called data marts "'[3; nine].

The concept of data warehouses is based on the idea of combining corporate data scattered across operational data processing systems, historical archives and other external sources. These sources may contain data that are not used directly in information processing systems, but are vital for DSS: legal framework (including tax forecasts), industry development plans, statistical data, electronic directories. As practice shows, a decision made on the basis of only internal data is often incorrect. The purpose of the concept of data warehouses is to clarify the differences in the characteristics of data in operating and analytical systems, to determine the requirements for data, are placed in the warehouse, to determine the general principles 
and stages of its construction, the main data sources, to give recommendations on solving potential problems arising during their unloading, cleaning, reconcile, transport and load the target warehouse database. The subject of the concept of data warehouses is not data analysis, but the data itself, that is, the concept of their preparation for further analysis. At the same time, the data warehouse concept defines not just a single logical view of corporate data, but the implementation of a single integrated data source.

Data warehousing technology originated in the United States and has since gained worldwide acceptance. The first data warehouses appeared in the early 80 s of the last century (then they were called atomic databases), but only by the end of the $80 \mathrm{~s}$ the need to integrate corporate information and its proper management was fully realized, and technical capabilities appeared for creation of the corresponding systems, at first the name "information warehouses" (Information Warehouse - IW) and only later received their modern name "data warehouses" (Data Warehouse - DW). In the early 90s, with the advent of technologies for extracting, transforming and loading data (Extraction, Transmission and Loading - ETL) and online analytical processing (OLAP), an active spread of data warehouses began in the commercial sector. This process was also facilitated by the publication of the first book by Bill Inmon [10], who is widely recognized as the "father of the data warehouse concept." Soon, data warehouse technology evolved into an advanced architecture known as the Corporate Information Factory (CIF).

Another important direction that contributed to the emergence of data warehouses was the emergence of decision support systems (DSS - Decision Support Systems) and information systems for decisions (EIS - Executive Information Systems). Without pretending to own their own intelligence, unlike everything that was discussed in the $60 \mathrm{~s}$ and 70 s and remained in the field of eternal ideas, the DSS and EIS systems turned out to be practically useful: they became prototypes of modern data extraction systems, online analytics, a new discipline corporate governance based on knowledge. DSS systems were initially set up for middle management, while EIS attempted to provide a more general and multidimensional view over the data field for corporate-level executives. These two technological ideas, deeply intersected with each other, appeared, most likely, the direct ancestors of the modern concept of data warehouses.

Using a neural network allows you to take into account the factors on the basis of which you can build short-term forecasts. Applying a neural network architecture and a database, you can get an efficient forecasting system. It is necessary to take into account external parameters with the inclusion of the corresponding input to the neural network. In this case, an algorithm is used to determine the importance and significance of the input variables, with the exclusion of parameters that have little impact. The advantage of neural networks is that the expert does not select a mathematical model of the time series behavior. The construction of a neural network model is carried out adaptively without the participation of an expert in the learning process. The disadvantage of this technique is the need for specialized software tools; the complexity of meaningful interpretation of neural networks and non-determinism. This refers to the so-called "black box", in which the logic of decision-making by the neural network is hidden from the expert. Thus, the model does not allow to unambiguously and transparently determine the contribution of each indicator to the improvement or deterioration of the financial condition of the enterprise. For this, there are algorithms for "extracting knowledge from a neural network" that formalize a list of logical rules, creating an expert system based on the network. However, these algorithms are not embedded in neural network packets, and the rule sets generated by such algorithms are quite voluminous.

However, we also believe that artificial neural networks have a major drawback: they model only the main elements of the human brain. Biological neurons are much more complex than their artificial counterparts. But technology is constantly improving, and 
network designers are constantly improving artificial neural networks, which are increasingly beginning to resemble a model of the human biological brain. So, having considered the advantages and disadvantages of artificial neural networks, we can conclude that they are an indispensable element in the activities of each enterprise and improve the quality of decisions made by managers at these enterprises. Since not all enterprises are able to develop their own neuro-system, it is possible to use already created programs. So, artificial neural networks are a promising and very robust analytical tool. The results of their implementation at the enterprise, in our opinion, will be:

1) improving product quality;

2) simplifying life by reducing the amount of mechanical work;

3) improving the accuracy of heavy calculations and predictions;

4) improving the accuracy of marketing forecasts;

5) reducing the level of crime in the field of high technologies.

\section{Conclusions}

Thus, artificial neural networks have become a dense part of our life and are now widely used in solving a wide variety of problems. They are actively used where conventional algorithmic solutions turn out to be ineffective or completely impossible. But neural networks cannot be considered universal for solving all computational problems. Today, neural networks are used to work in relatively narrow areas. However, progress does not stand still and neural networks continue to confidently penetrate our lives. They have already made it possible to cope with a number of difficult problems and promise to create new programs and devices capable of solving problems that only a person can do so far. As a prospect for further research in this direction, we determined the consideration of the possibilities of using artificial neural networks in the context of the features of the industry focus of individual enterprises.

\section{References}

1. E.V. Bodyansky, O.G. Rudenko, Artificial neural networks: architectures, training, applications, 369 (2004)

2. V.I. Bozhich O.B., Lebedev Yu.L. Schnitzer, Perspective information technologies and intelligent systems, 1, 21 (2011)

3. B. Inmon, Data Warehouse Environment, 4, 41(2000)

4. A.A. Yezhov, S.A. Shumsky, Neuro-computing and its applications in economics and business, 224 (1998)

5. V.V. Kruglov, V.V. Borisov, Artificial neural networks. Theory and practice, 382 (2002)

6. A.A. Barsegyan, M.S. Kupriyanov, V.V. Stepanenko, Methods and models of data analysis: OLAP and Data Mining, 336 (2004)

7. S. Osovsky, Neural networks for information processing , 344 (2010)

8. Haykin Simon, Neural networks, Complete course, 2, 1104 (2006)

9. G. Edelstein, ComputerWeek, 16, 32 (1996)

10. W.H. Inmon, Building the Data Warehouse, QED / Wiley, 312 (1996) 